Revista Brasileira de Agricultura Irrigada v.12, nº.3, p. 2661 - 2672, 2018

ISSN 1982-7679 (On-line)

Fortaleza, CE, INOVAGRI - http://www.inovagri.org.br

DOI: $10.7127 /$ rbai.v12n300830

Protocolo 830.18 - 05/12/2017 Aprovado em 03/04/2018

\title{
RESPOSTAS MORFOLÓGICAS E FISIOLÓGICAS DE CULTIVARES DE CANA- DE-AÇÚCAR SOB ESTRESSE HÍDRICO NO SEGUNDO CICLO DE CULTIVO
}

\author{
Sebastião de Oliveira Maia Júnior ${ }^{1}$, João Antônio Carvalho Silva ${ }^{2}$, Karolyne Priscila Oliveira \\ Santos $^{3}$, Daniel Rocha Cordeiro ${ }^{4}$, José Vieira Silva ${ }^{5}$, Lauricio Endres ${ }^{6}$
}

\begin{abstract}
RESUMO
A ocorrência cada vez mais frequente de secas prolongadas tem se tornado um fator bastante negativo na produção de cana-de-açúcar. Nessas condições, as plantas são afetadas podendo variar entre cultivares. Dessa forma, objetivou-se com esse trabalho avaliar respostas morfológicas e fisiológicas de cultivares de cana-de-açúcar em condições de estresse hídrico no segundo ciclo. Para tanto, foi realizado um experimento em fatorial $6 \times 3$, sendo seis cultivares de cana-de-açúcar: RB72910, RB99382, RB72454, RB92579, RB855536 e RB931011, e três tratamentos hídricos, com base no conteúdo de água disponível no solo (CAD) e definidos como: controle, 80 a 100\% (AD); estresse hídrico moderado, 40 a 60\% (AD) e estresse hídrico severo, 0 a 20\% (AD). O estresse hídrico afetou todas as características morfológicas e fisiológicas, havendo interação entre tratamentos hídricos e cultivares para o índice SPAD e o número de folhas. A cultivar RB72454 foi a mais sensível ao estresse hídrico com menor índice SPAD e número de folhas sob estresse severo. Por outro lado, a RB72910 e RB92579 foram as menos afetadas, tendo maior índice SPAD e número de folhas sob estresse severo.
\end{abstract}

Palavras-chave: área foliar, estresse abiótico, índice SPAD, número de folhas.

\section{MORPHOLOGICAL AND PHYSIOLOGICAL RESPONSES OF CUCTIVARS SUGARCANE UNDER DROUGHT STRESS IN THE SECOND CYCLE OF CULTIVATION}

\footnotetext{
${ }^{1}$ Doutor em Agronomia, Centro de Ciências Agrárias, Universidade Federal de Alagoas, Rio Largo, AL, Brasil. E-mail: juniormaiagrari@hotmail.com

${ }^{2}$ Graduado em Agronomia, Centro de Ciências Agrárias, Universidade Federal de Alagoas, Rio Largo, AL, Brasil. E-mail: joao.ufal.2013@gmail.com

${ }^{3}$ Graduanda em Agronomia, Centro de Ciências Agrárias, Universidade Federal de Alagoas, Rio Largo, AL, Brasil. E-mail: karoline.15@hotmail.com

${ }^{4}$ Graduando em Agronomia, Centro de Ciências Agrárias, Universidade Federal de Alagoas, Rio Largo, AL, Brasil. E-mail: daniel08rocha@gmail.com

${ }^{5}$ Prof Doutor, Departamento de Agronomia, Universidade Federal de Alagoas, Arapiraca, AL, Brasil. E-mail: jovisi@yahoo.com.br

${ }^{6}$ Prof Doutor, Centro de Ciências Agrárias, Universidade Federal de Alagoas, Rio Largo, AL, Brasil. E-mail: lauricioendres@hotmail.com
} 


\begin{abstract}
The frequent occurrence of prolonged droughts has become a very negative factor in the production of sugarcane. These conditions, the plants are affected being able to vary among cultivars. Thus, the objective of this work was to evaluate morphological and physiological responses of sugarcane cultivars under conditions of drought stress in the second cycle. Therefore, a 6 x 3 factorial experiment was realized, with six sugarcane cultivars: RB72910, RB99382, RB72454, RB92579, RB855536 and RB931011, and three water treatments, based on the available soil water content (AWC) and defined as: control, 80 to 100\% (AWC); moderate water stress, 40 to $60 \%$ (AWC) and severe water stress, 0 to $20 \%$ (AWC). Water stress affected all the morphological and physiological characteristics, with interaction between water treatments and cultivars for the SPAD index and the number of leaves. The cultivar RB72454 was the more sensitive to water stress with lower SPAD index and number of leaves under severe stress. On the other hand, RB72910 and RB92579 were the less affected, having greater SPAD index and number of leaves under severe stress.
\end{abstract}

Keywords: leaf area, abiotic stress, SPAD index, number of leaves.

\section{INTRODUÇÃO}

A cana-de-açúcar (Saccharum spp.) é uma cultura de grande importância econômica mundial, devido à sua utilização como fonte de matéria-prima para a indústria alimentícia e produção de biocombustível renovável. O Brasil tem uma área plantada com cana-deaçúcar de aproximadamente 8.838,5 mil hectares, distribuídas em todos Estados produtores conforme suas características climáticas. O Estado de São Paulo é o maior produtor com 4558,4 mil ha de área plantada, seguido por Goiás com 939,7; Minas Gerais com 841,7; Paraná com 624,6; Mato Grosso do Sul com 646,3; Alagoas com 301,7 e Pernambuco com 259,5 mil ha (CONAB, 2017).

Nesse contexto, mesmo com todo crescimento da produção na maioria das regiões brasileiras, especialmente a região Nordeste, a deficiência hídrica é apontada como um dos fatores ambientais responsáveis pelas maiores quedas na produção da cana-de-açúcar, uma vez que as chuvas não são distribuídas uniformemente ao longo do ano (VIEIRA et al., 2014). Com isso, um dos grandes desafios tem sido manter a produtividade da cultura em regiões passíveis de restrição hídrica (SILVA et al., 2012), o que vem sendo feito através da utilização de cultivares mais tolerantes, tornando fundamental a seleção de cultivares na tolerância à deficiência hídrica (SILVA et al., 2007; 2013).

As plantas de cana-de-açúcar, sob condições de déficit hídrico, podem ser afetadas com redução das características morfológicas como a altura de plantas, o número de folhas verdes e a área foliar (SILVA et al., 2007; SILVA; PINCELLI, 2012). Quando ocorrem drásticas reduções no crescimento da cana-deaçúcar, consequentemente, são afetados seu desenvolvimento e rendimento final (SILVA et al., 2012).

Além disso, a fisiologia das plantas também é afetada pela restrição hídrica, como o déficit de pressão de vapor entre as folhas e o ar (ENDRES et al, 2010; SILVA et al., 2013). O estresse hídrico pode elevar muito essa característica fisiológica e acabar influenciando na eficiência do uso da água, além de aumentar a temperatura das folhas levando a outros distúrbios fisiológicos, como a síntese de clorofila (SARAIVA et al., 2014; VIEIRA et al., 2014).

Quando a biossíntese de clorofila é afetada, ocorre a diminuição da eficiência de absorção da energia luminosa, levando a sérios danos no aparelho fotossintético das plantas (SILVA et al., 2007). Essa situação pode ser avaliada pela estimativa do conteúdo relativo de clorofila ou índice SPAD, que se apresenta como um parâmetro confiável na seleção de cultivares tolerantes à seca, como observado em 
cana-de-açúcar (SILVA et al., 2014) e milho (MAGALHÃES et al., 2009).

Vários estudos vêm sendo realizados para seleção de cultivares de cana-de-açúcar mais tolerantes ao déficit hídrico (MEDEIROS et al., 2013; SILVA et al., 2013). No entanto, a maioria desses trabalhos foram realizados no primeiro ciclo de cultivo, e em vasos (MEDEIROS et al., 2013), que a depender do tamanho, pode ser um fator limitante no crescimento das raízes (GONÇALVES et al., 2010). Dessa maneira, não há registros de trabalhos realizados com cana-de-açúcar no segundo ciclo de cultivo, uma vez que o ciclo pode influenciar nas respostas de tolerância das cultivares ao estresse, bem como em vasos de grande volume que proporcionam maior exploração do sistema radicular.

Nossa hipótese é que as diferenças morfológicas e fisiológicas entre cultivares de cana-de-açúcar no primeiro ciclo, relatadas na literatura (GONÇALVES et al. 2010; MEDEIROS et al. 2013) também se expressam no segundo ciclo de cultivo.

Diante o exposto, este estudo teve como objetivo avaliar respostas morfofisiológicas de cultivares de cana-de-açúcar no segundo ciclo de cultivo, sob condições de estresse hídrico, possibilitando identificar cultivares melhor adaptadas ao déficit hídrico que possam ser utilizadas em programas de melhoramento genético da cultura.

\section{MATERIAL E MÉTODOS}

O experimento foi conduzido sob as coordenadas $9^{\circ} 28^{\prime} \mathrm{S}, 35^{\circ} 49^{\prime} \mathrm{W}$, a $127 \mathrm{~m}$ de altitude. O delineamento experimental foi em blocos casualizados, em esquema fatorial 6 × 3, sendo seis cultivares de cana-de-açúcar e três tratamentos hídricos, distribuídos em quatro blocos, totalizando 72 parcelas experimentais. As cultivares de cana-de-açúcar utilizadas foram RB72910, RB99382, RB72454, RB92579, RB855536 e RB931011. Os tratamentos hídricos foram baseados na capacidade de água disponível no solo (CAD), e definidos como: controle, 80 a 100\% (AD); estresse hídrico moderado, 40 a $60 \%$ (AD) e estresse hídrico severo, 0 a $20 \%$ (AD).

A parcela experimental foi composta por um vaso de 0,485 m de diâmetro médio e 0,99 $\mathrm{m}$ de altura, preenchido com aproximadamente $180 \mathrm{~kg}$ de solo destorroado, peneirado e homogeneizado. Os vasos foram distribuídos em arranjo espacial de $1,0 \times 1,0 \mathrm{~m}$ entre as linhas e fileiras, a céu aberto.

O solo utilizado foi um Latossolo Amarelo coeso. As análises físico-químicas foram realizadas seguindo a metodologia da Embrapa (1997), e a curva de retenção de umidade foi estimada utilizando-se a metodologia de Richards (1965), cujos resultados encontram-se na Tabela 1.

Os rebolos utilizados para o plantio (19/02/2014) foram padronizados levando-se em consideração a idade, estado sanitário, e região do colmo da cana semente. Para garantir melhor homogeneidade das plântulas, os rebolos foram plantados previamente em bandejas plásticas mantidas sob telado até que as plântulas atingissem três folhas definidas, aptas ao transplantio. Decorridos 30 dias após o plantio, foram selecionadas três plântulas, de tamanho uniforme, para cada vaso.

Tabela 1. Propriedades químicas e físicas do solo utilizado no experimento.

\begin{tabular}{|c|c|}
\hline Análise do solo & \\
\hline \multicolumn{2}{|c|}{ Química } \\
\hline Condutividade elétrica & $0,32 \mathrm{dS} \mathrm{m}^{-1}$ \\
\hline $\mathrm{pH}$ & 6,3 \\
\hline $\mathrm{Ca}^{2+}$ & $7,61 \mathrm{cmol}_{\mathrm{c}} \mathrm{kg}^{-1}$ \\
\hline $\mathrm{Mg}^{2+}$ & $4,41 \mathrm{cmol}_{\mathrm{c}} \mathrm{kg}^{-1}$ \\
\hline $\mathrm{Na}^{+}$ & $0,26 \mathrm{cmol}_{\mathrm{c}} \mathrm{kg}^{-1}$ \\
\hline $\mathrm{K}^{+}$ & $0,18 \mathrm{cmol}_{\mathrm{c}} \mathrm{kg}^{-1}$ \\
\hline $\mathrm{P}$ & $49 \mathrm{mg} \mathrm{kg}^{-1}$ \\
\hline
\end{tabular}




\begin{tabular}{|c|c|}
\hline $\begin{array}{l}\mathrm{Al}^{3+} \\
\text { Matéria orgânica }\end{array}$ & $\begin{array}{l}0,00 \mathrm{cmol}_{\mathrm{C} \mathrm{kg}} \mathrm{kg}^{-1} \\
35,60 \mathrm{~g} \mathrm{~kg}^{-1}\end{array}$ \\
\hline \multicolumn{2}{|r|}{ Física } \\
\hline Porosidade total & $56,2 \%$ \\
\hline Densidade global & $1,17 \mathrm{~g} \mathrm{~cm}^{-3}$ \\
\hline Areia & $637,6 \mathrm{~g} \mathrm{~kg}^{-1}$ \\
\hline Silte & $205,9 \mathrm{~g} \mathrm{~kg}^{-1}$ \\
\hline Argila & $156,5 \mathrm{~g} \mathrm{~kg}^{-1}$ \\
\hline Classificação textural & Franco argilo arenoso \\
\hline Tensão (MPa) & Conteúdo de água (\%) \\
\hline 0,033 & 27,72 \\
\hline 1,5 & 14,76 \\
\hline Água disponível & 12,96 \\
\hline
\end{tabular}

Aos 240 dias após o plantio, a cana-planta foi cortada iniciando-se o segundo ciclo. Posteriormente, os vasos foram irrigados, regularmente, próximo à capacidade de campo até o momento de implantação dos tratamentos hídricos que tiveram início aos 60 dias após o corte (DAC). Foi realizado o desbaste do perfilhamento deixando-se seis plantas de tamanho uniforme em cada vaso.

Durante o período de estresse hídrico a umidade do solo foi monitorada, em cada vaso por meio de um sistema de sonda de monitoramento de umidade de solo (Moisture Meter PR2, Delta T Devices, England) que avalia a umidade a cada $10 \mathrm{~cm}$ até a profundidade de $40 \mathrm{~cm}$. A reposição da água foi feita por sistema de irrigação pressurizada, com um emissor por parcela, deixando-se cada tratamento hídrico na sua faixa de umidade (Figura 1A). Os dados climáticos referentes ao período experimental foram obtidos por uma estação agrometeorológica automática, localizada a aproximadamente $200 \mathrm{~m}$ do experimento. Os dados foram registrados a cada dez minutos, onde se obteve a precipitação pluvial (Figura 1B), a temperatura do ar média (Figura 1C) e a umidade relativa do ar média (Figura 1D). 

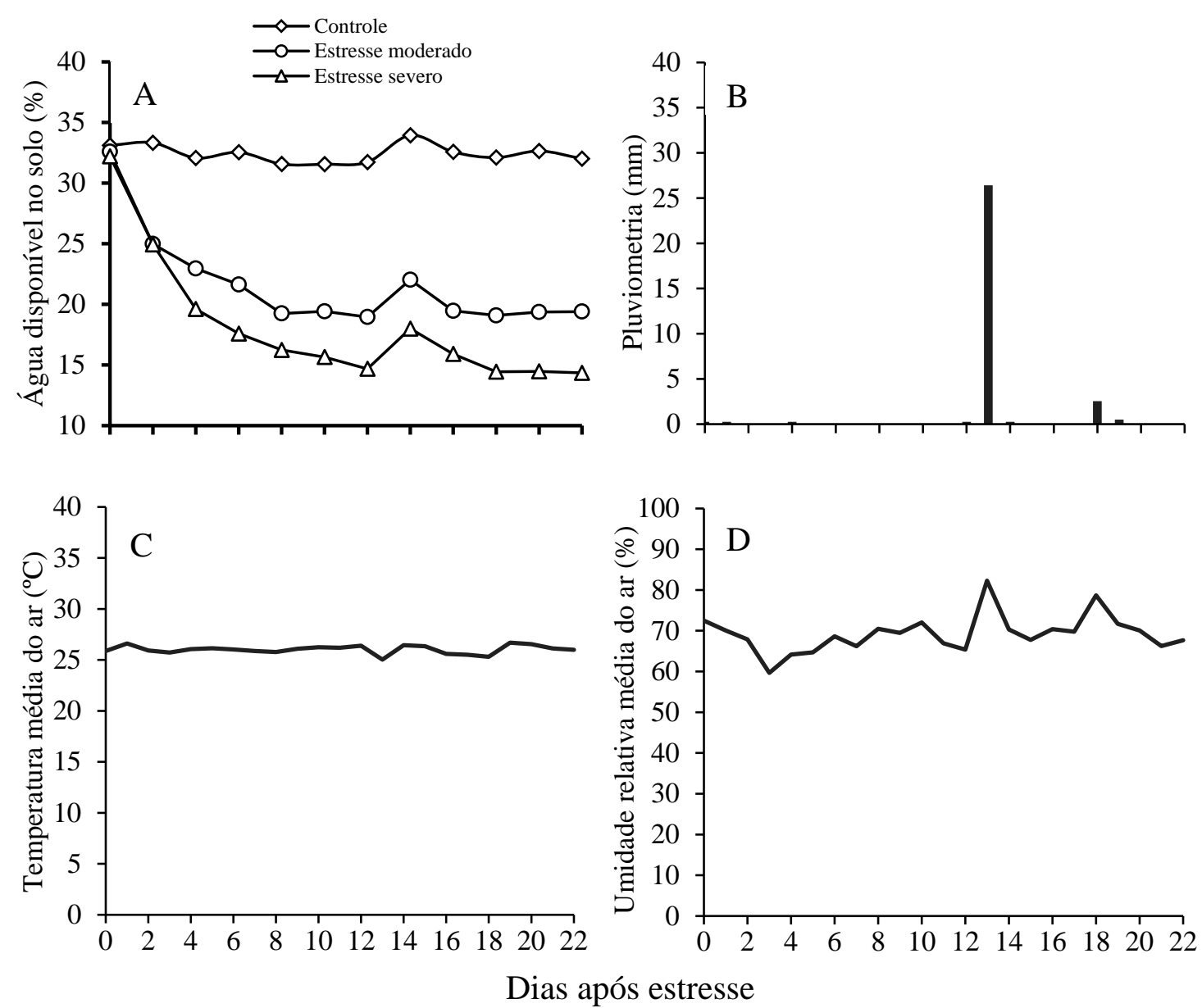

Figura 1. Umidade do solo com cultivares de cana-de-açúcar submetidas ao estresse hídrico no segundo ciclo (A), pluviometria (B), temperatura média do ar (C) e umidade relativa média do ar (D) durante o período experimental.

Aos 22 dias após o início do estresse hídrico (82 DAC) foram realizadas as seguintes avaliações fisiológicas: teor relativo de água na folha, índice SPAD, temperatura foliar e déficit de pressão de vapor (folha-ar). Todas essas avaliações fisiológicas foram realizadas na folha+1, de acordo com a classificação Kuijper (VAN DILLEWIJN, 1952).

O teor relativo de água foi quantificado extraindo-se três discos $\left(0,85 \mathrm{~cm}^{2}\right)$ da folha +1 . Primeiramente foi determinada a massa do tecido fresco dos discos em balança analítica. Posteriormente, os respectivos discos foram reidratados usando água deionizada por $24 \mathrm{~h}$ em ausência de luz, transcorrido esse tempo foi retirado o excesso de água com lenço de papel, e determinada a massa do tecido túrgido. A massa do tecido seco foi obtida depois que os discos foram secos por $48 \mathrm{~h}$ em estufa de circulação forçada de ar a $65^{\circ} \mathrm{C}$. O TRA foi calculado conforme Barrs e Weatherley (1962): TRA = [(MF - MS ) / (MT - MS $)]$ x 100; em que: MF corresponde a massa do tecido fresco, MT a massa do tecido túrgido, e MS a massa do tecido seco.

O índice SPAD foi mensurado utilizandose um clorofilômetro portátil modelo SPAD502, sendo aferidas três leituras na região do terço médio da folha +1 (SILVA et al., 2013). Posteriormente, obteve-se a média geral por folha.

A temperatura foliar e o déficit de pressão de vapor foram avaliados com um analisador de gás, modelo Li-6400XT (Licor, EUA) entre as 8:00 e 10:00 horas da manhã.

Na ocasião, também foram realizadas as seguintes avaliações morfológicas: altura de planta $(\mathrm{cm})$, diâmetro do colmo (mm), número 
de folhas expandidas com pelo menos 20\% de área verde, e a área foliar $\left(\mathrm{cm}^{2}\right)$, calculada conforme Hermann e Câmara (1999).

Os dados foram submetidos à análise de variância pelo teste $\mathrm{F}$, e quando detectada diferença significativa fez-se teste de médias para os fatores isolados e os desdobramentos das interações, utilizando-se o teste de Tukey $(\mathrm{p}<0,05)$.

\section{RESULTADOS E DISCUSSÃO}

Os tratamentos hídricos afetaram todas as variáveis fisiológicas estudadas (Tabela 2), enquanto que, somente o déficit de pressão de vapor (folha-ar) e a temperatura foliar não variaram entre as cultivares.

Tabela 2. Resumo da análise de variância das variáveis: déficit de pressão de vapor folha-ar (DPV), temperatura da folha (Tf), teor relativo de água na folha (TRA), índice SPAD, altura de plantas (AP), diâmetro do colmo (DC), número de folhas (NF) e área foliar (AF) em cultivares de cana-de-açúcar no segundo ciclo de cultivo sob diferentes tratamentos hídricos.

\begin{tabular}{lccccc}
\hline \multirow{2}{*}{ FV } & GL & \multicolumn{4}{c}{ Quadrados médios } \\
\cline { 2 - 5 } W & 2 & DPV & Tf & TRA & SPAD \\
C & $1,08^{*}$ & $1,51^{*}$ & $1,060,02^{*}$ & $575,72^{*}$ \\
(W x C) & 5 & $0,01^{\text {ns }}$ & $0,05^{\text {ns }}$ & $32,97^{*}$ & $73,91^{*}$ \\
CV (\%) & 10 & $0,02^{\text {ns }}$ & $0,13^{\text {ns }}$ & $6,61^{\text {ns }}$ & $21,81^{*}$ \\
& & 8,4 & 1,6 & 3,3 & 6,2 \\
W & & & & NF & AF \\
C & 2 & $450,50^{* *}$ & $74,705^{* *}$ & $1,733^{* *}$ & $1.999 .562,2^{* *}$ \\
(W x C) & 5 & $11.057,54^{* *}$ & $60,232^{* *}$ & $153,041^{* *}$ & $1.999 .562,2^{* *}$ \\
CV (\%) & 10 & $192,89^{\text {ns }}$ & $2,811^{\text {ns }}$ & $0,925^{* *}$ & $96.856,2^{\text {ns }}$ \\
\hline
\end{tabular}

FV: Fontes de variação; GL: graus de liberdade; W: Tratamentos hídricos; C: Cultivares; CV: coeficiente de variação; *, **: significativo $(\mathrm{p}<0,05$ e 0,01$)$, respectivamente, pelo teste Tukey; ns: não-significativo.

O estresse hídrico severo aumentou o déficit de pressão de vapor (folha-ar) em $26,7 \%$ em relação ao tratamento controle (Figura 2A), enquanto 0 aumento da temperatura foliar foi em média 3\%, nas mesmas condições (Figura 2B), não havendo diferença entre as cultivares.

O acréscimo do DPV folha-ar em cultivares de cana-de-açúcar sob déficit hídrico ocorre devido à redução da perda de água pelas folhas, e tem funcionado efetivamente como um parâmetro de sinalização de estresse em plantas (ENDRES et al., 2010; SILVA et al., 2013). A relação entre o aumento do DPV e da
Tf pode promover o aquecimento da superfície foliar com perda da capacidade de dissipação térmica da planta (VIEIRA et al., 2014; SARAIVA et al., 2014).

O teor relativo de água na folha foi afetado pelo déficit hídrico reduzindo aproximadamente 6,1 e $16,3 \%$ sob estresse hídrico moderado e severo, respectivamente, em relação ao tratamento controle (Figura 2C). Entre as cultivares, a RB931011 manteve o maior teor relativo de água, no entanto, semelhante às demais com valor médio de $87 \%$, exceto a RB72454 que teve menor TRA, aproximadamente $82 \%$ (Figura 2D). 

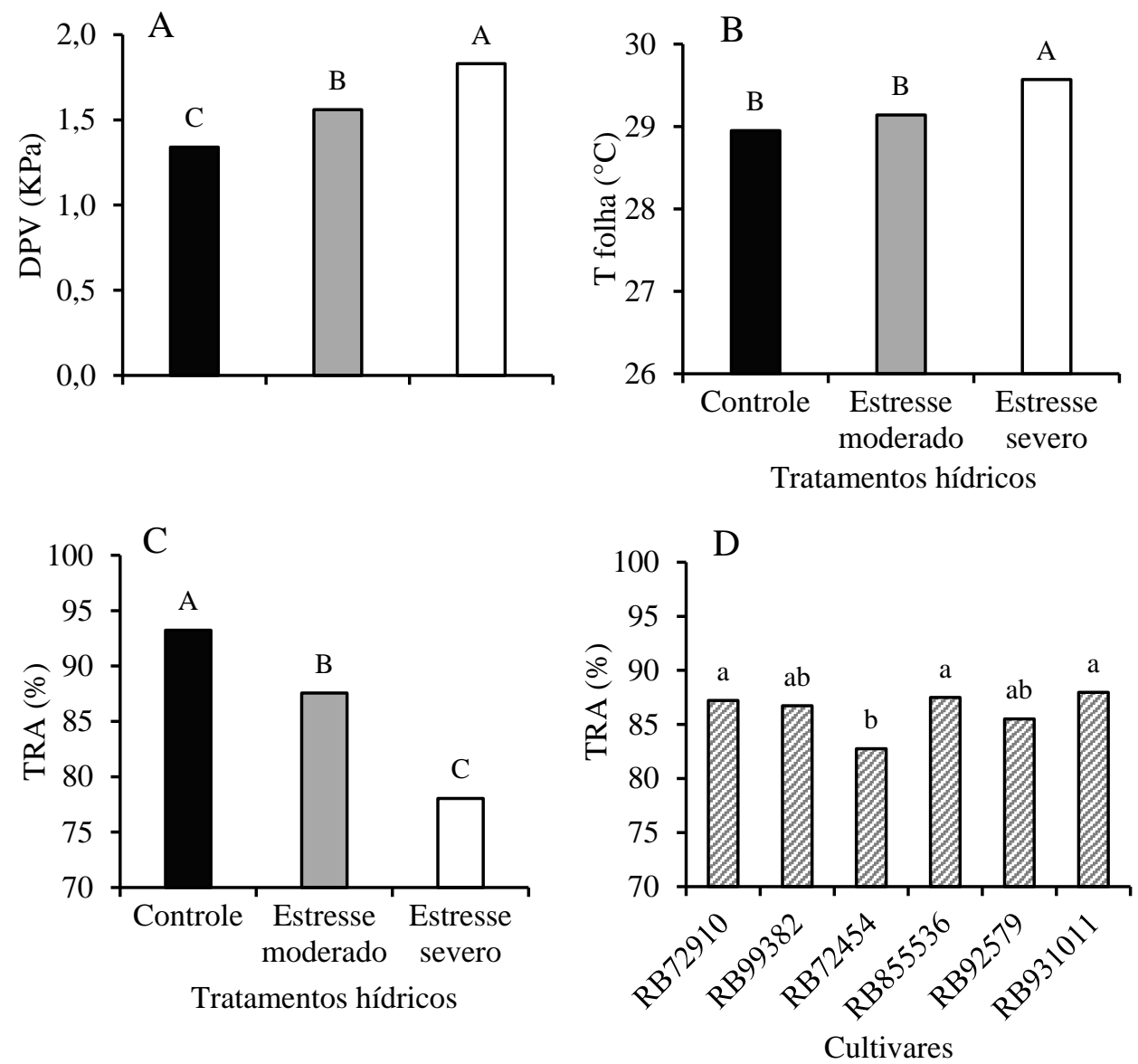

Figura 1. Déficit de pressão de vapor folha-ar (A), temperatura foliar (B) e teor relativo de água (C e D) em cultivares de cana-de-açúcar no segundo ciclo de cultivo sob diferentes tratamentos hídricos: controle, estresse moderado e estresse severo. Letras maiúsculas diferentes indicam diferenças significativas entre tratamentos hídricos e letras minúsculas indicam diferenças significativas entre cultivares, pelo teste de Tukey $(\mathrm{p}<0,05)$.

O baixo TRA indica maior desidratação dos protoplastos, o que pode levar a outros danos fisiológicos (SILVA et al., 2007; ENDRES et al., 2010), como foi observado nesse estudo com a cultivar RB72454 que teve baixo TRA e índice SPAD. O estresse hídrico influencia negativamente no TRA em cana-de-açúcar, e cultivares que têm maior redução possuem indicativo de sensibilidade à seca (SILVA et al., 2007; 2013).
O índice SPAD teve efeito da interação entre tratamentos hídricos e cultivares (Tabela 2). A cultivar RB72454 foi a que teve o índice SPAD mais afetado pelo estresse, tanto moderado quanto severo, com reduções de 37,2 e 46\%, respectivamente, em relação ao tratamento controle (Figura 3). Por outro lado, as cultivares RB72910, RB855536 e RB92579 foram menos afetadas pelo estresse severo, com reduções de 14, 20 e $21 \%$, respectivamente. 


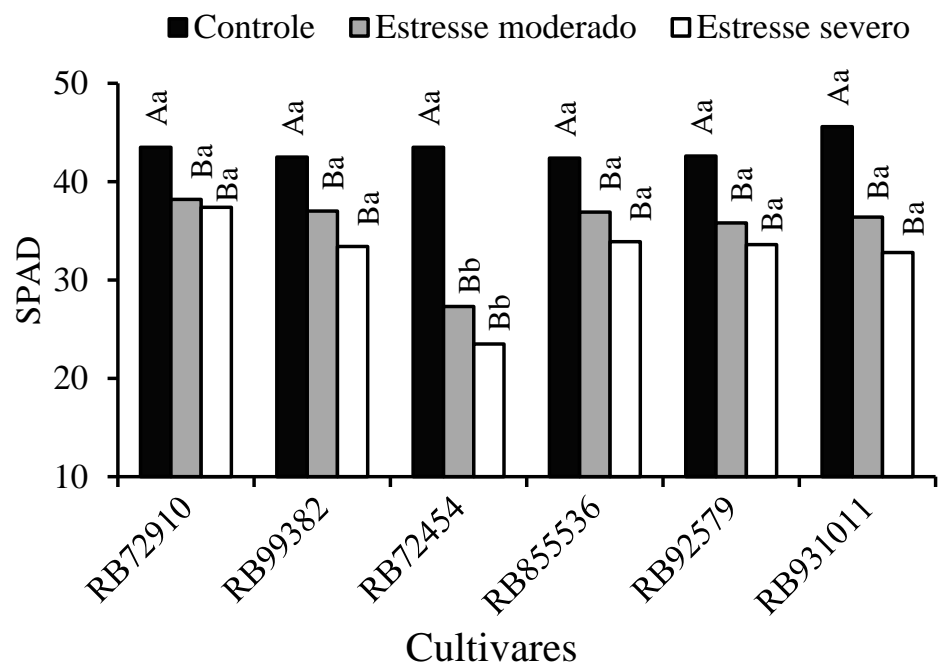

Figura 3. Conteúdo estimado de clorofila - SPAD, em cultivares de cana-de-açúcar no segundo ciclo de cultivo sob diferentes tratamentos hídricos. Letras maiúsculas diferentes indicam diferenças significativas entre tratamentos hídricos em cada cultivar e letras minúsculas indicam diferenças significativas entre cultivares em cada tratamento hídrico, pelo teste de Tukey $(\mathrm{p}<0,05)$.

O SPAD tem sido bastante eficiente no diagnóstico dos pigmentos cloroplastídicos, pois é bem correlacionado com os teores de clorofilas e de carotenoides (SILVA et al., 2012; 2014). Dessa maneira, trata-se de uma boa ferramenta para diagnosticar a integridade do aparato fotossintético de folhas, podendo ajudar nas interpretações do processo fotoquímico das plantas (SILVA et al., 2014). Em cultivares de cana-de-açúcar sob estresse hídrico, as mais sensíveis tiveram maior redução do índice SPAD, o qual foi relacionado com a diminuição da produtividade e rendimento industrial da cultura (SILVA et al., 2012; 2014; VIEIRA et al., 2014). De maneira semelhante, o índice SPAD também teve maior redução em cultivares de milho mais sensíveis ao déficit hídrico (MAGALHÃES et al., 2009), se confirmando como uma técnica eficiente na seleção de materiais tolerantes à seca.

Todas as características morfológicas foram alteradas pelos tratamentos hídricos além de diferirem entre as cultivares (Tabela 2). No entanto, apenas para o número de folhas houve interação entre os tratamentos hídricos e as cultivares.

A altura de plantas reduziu aproximadamente 38\% com o estresse severo (Figura 4A). Entre as cultivares, a RB931011, RB92579 e RB855536 foram as mais altas, enquanto a RB72910 foi a cultivar mais baixa, independente dos tratamentos hídricos (Figura 4B). De maneira semelhante, o diâmetro do colmo reduziu aproximadamente $13 \%$ com o estresse severo (Figura 4C). Entre as cultivares, a RB72910 e RB99382 foram as que tiveram menor diâmetro, enquanto as demais tiveram maior diâmetro, independente dos tratamentos hídricos (Figura 4D).

A área foliar também reduziu aproximadamente $44,2 \%$ com o estresse severo (Figura 4E). Entre as cultivares, a RB99382 teve a menor área foliar, enquanto a RB855536 teve a maior, independente dos tratamentos hídricos (Figura 4F). 

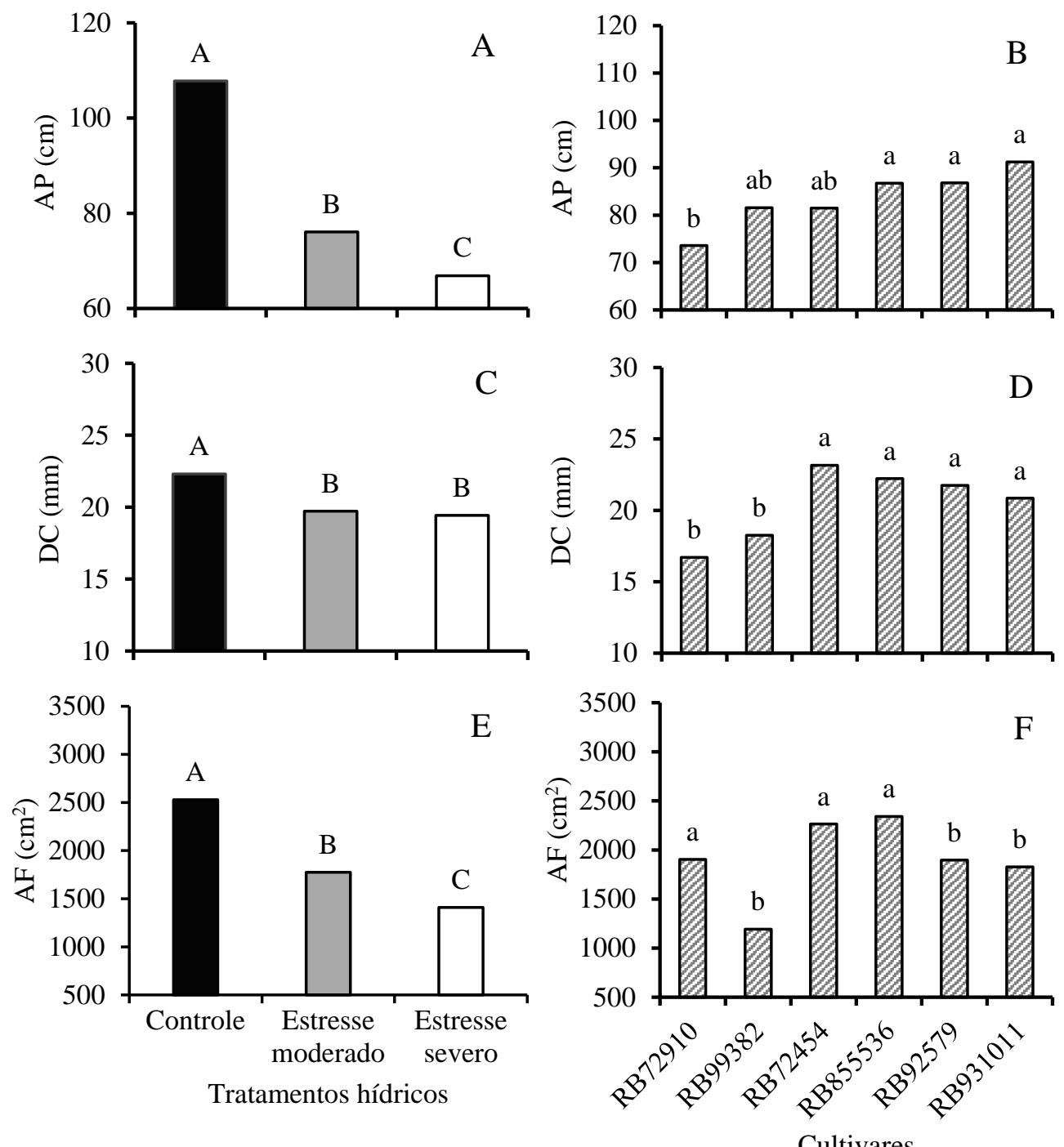

Figura 4. Altura de plantas (A e B) diâmetro do colmo (C e D) e área foliar (E e F) em cultivares de cana-deaçúcar no segundo ciclo de cultivo sob diferentes tratamentos hídricos: controle, estresse moderado e estresse severo. Letras maiúsculas diferentes indicam diferenças significativas entre tratamentos hídricos e letras minúsculas indicam diferenças significativas entre cultivares, pelo teste de Tukey $(\mathrm{p}<0,05)$.

A redução da disponibilidade hídrica limita o crescimento das plantas resultando em restrições no alongamento e divisão celular, o que afeta negativamente na morfologia da planta (JALEEL et al., 2009; SILVA et al., 2012), como pode se observar na altura de planta, diâmetro do colmo e área foliar sob estresse hídrico severo. Essas características indicaram predominância intrínseca de cada cultivar sem influência dos tratamentos hídricos impossibilitando, portanto, de utilizá-las na seleção das cultivares ao déficit hídrico no período estudado.

Por um lado, as particularidades das características morfológicas de cada cultivar encontradas nesse trabalho, independente dos tratamentos hídricos, também foi observada em outros estudos com cana-de-açúcar (DIAS et al., 2012). Já por outro lado, a ausência de alterações entre cultivares pela limitação hídrica pode ter ocorrido devido ao tempo de exposição ao estresse, como relatado por Holanda et al. (2014). Para esses autores, é necessário um longo período de estresse para que alterações morfológicas tornem-se mais evidentes, e como em nosso estudo, o tempo de exposição ao estresse foi curto (22 dias) não foi possível identificar diferenças entre as cultivares, exceto para o número de folhas.

$\mathrm{O}$ estresse severo afetou o número de folhas com maior intensidade nas cultivares RB931011 e RB72454 reduzindo em 56 e 
$53,7 \%$, respectivamente, enquanto as cultivares RB72910 e RB92579 foram menos afetadas, com redução de 35 e 47\%, respectivamente (Figura 5).

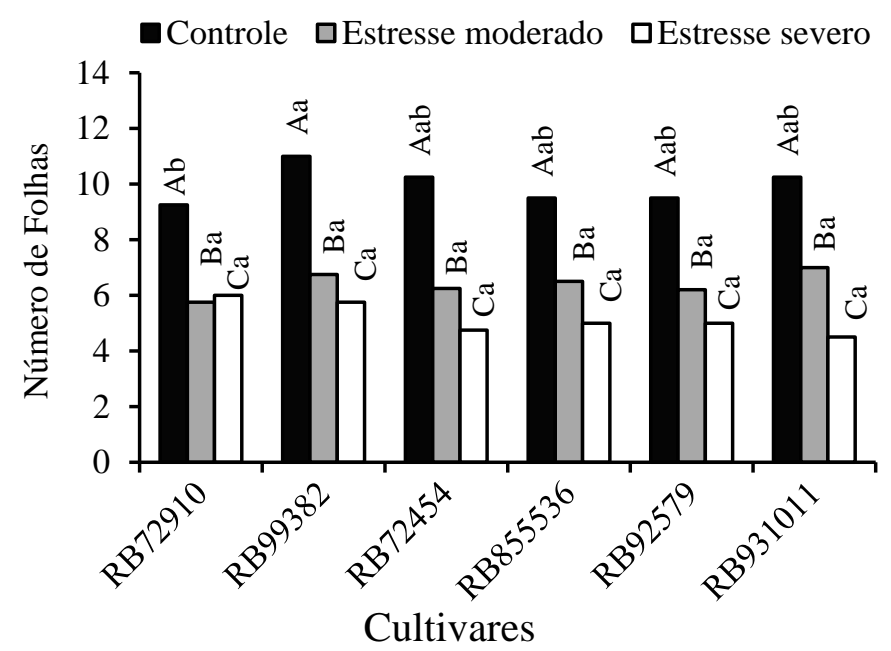

Figura 5. Número de folhas em cultivares de cana-de-açúcar no segundo ciclo de cultivo sob diferentes tratamentos hídricos. Letras maiúsculas diferentes indicam diferenças significativas entre tratamentos hídricos em cada cultivar e letras minúsculas indicam diferenças significativas entre cultivares em cada tratamento hídrico, pelo teste de Tukey $(\mathrm{p}<0,05)$.

A manutenção de folhas verdes em cultivares de cana-de-açúcar sob déficit hídrico pode ser um indicativo de tolerância (PINCELLI; SILVA, 2012). De acordo com esses autores, cultivares que mantém um maior número de folhas verdes no início do desenvolvimento, por período prolongado de estresse, são mais produtivas. Dessa maneira, nossos resultados apontam que as cultivares RB72910 e RB92579 têm maior adaptação a condições limitantes de água.

\section{CONCLUSÕES}

As características morfológicas não se alteram entre cultivares com pouco tempo de exposição ao estresse hídrico, com exceção do número de folhas.

Aos 22 dias após estresse hídrico, a cultivar RB72454 tem menor índice SPAD e baixo número de folhas sob estresse severo, sendo indicada como sensível ao estresse hídrico. De outra forma, as cultivares RB72910 e RB92579 reduzem pouco o número de folhas e o índice SPAD sob condição de estresse severo, indicando melhor adaptação ao estresse.

\section{REFERÊNCIAS BIBLIOGRÁFICAS}

BARRS, H. D.; WEATHERLEY, P. E. A reexamination of the relative turgidity technique for estimating water deficits in leaves. Australian Journal of Biological Sciences, v. 15, p. 413-428, 1962.

CONAB - Companhia Nacional de Abastecimento. Acompanhamento da safra brasileira- Cana, v. 4 - Safra 2017/18, n. 1 Primeiro levantamento, Brasília, p. 1-57, abril 2017.

DIAS, C. M. O.; CORSATO, C. E.; SANTOS, V. M.; SANTOS, A. F. S. Indicadores fitotécnicos, de produção e agroindustriais em cana de açúcar cultivada sob dois regimes hídricos. Revista Caatinga, v. 25, n. 3, p. 58-65, 2012.

EMBRAPA - Empresa Brasileira de Pesquisa Agropecuária. Centro Nacional de Pesquisa de Solos, Manual de Métodos de Análise de Solos. 2.ed. Rio de Janeiro, Embrapa, 1997. 212p. 
ENDRES, L.; SILVA, J. V.; FERREIRA, V. M.; BARBOSA, G. D. S. Photosynthesis and water relations in Brazilian sugarcane. Open Agriculture Journal, v. 4, n. 3, p. 31-37, 2010.

GONÇALVES, E. R.; FERREIRA, V. M.; SILVA, J. V.; ENDRES, L.; BARBOSA, T. P.; DUARTE, W. G. Trocas gasosas e fluorescência da clorofila a em variedades de cana-de-açúcar submetidas à deficiência hídrica. Revista Brasileira de Engenharia Agrícola e Ambiental, v. 14, p. 378-386, 2010.

HERMANN, E. R.; CÂMARA, G. M. S. Um método simples para estimar a área foliar da cana-de-açúcar. STAB, Açúcar, Álcool e Subprodutos, Piracicaba, v. 17, p. 32-34. 1999.

HOLANDA, L. A.; SANTOS, C. M.; SAMPAIO NETO, G. D.; SOUSA, A. P.; E SILVA, M. A. Variáveis morfológicas da canade-açúcar em função do regime hídrico durante o desenvolvimento inicial. Irriga, v. 19, p. 573584, 2014.

JALEEL C. A.; MANIVANNAN, P.; WAHID, A.; FAROOQ, M.; AL-JUBURI, H. J.; SOMASUNDARAM, R.; PANNEERSELVAM, R. Drought stress in plants: a review on morphological characteristics and pigments composition. International Journal of Agriculture \& Biology, v. 11, n.1, p. 100-105, 2009.

MAGALHÃES, P. C.; SOUZA, T. C.; ALBUQUERQUE, P. E. P.; KARAM, D.; MAGALHÃES, M. M.; CANTÃO, F. R. O. Caracterização ecofisiológica de linhagens de milho submetidas à baixa disponibilidade hídrica durante o florescimento. Revista Brasileira de Milho e Sorgo, v. 8, n. 3, p. 223232, 2009.

MEDEIROS, D. B.; SILVA, E. C.; NOGUEIRA, R. J. M. C.; TEIXEIRA, M. M.; BUCKERIDGE, M. S. Physiological limitations in two sugarcane varieties under water suppression and after recovering. Theoretical and Experimental Plant Physiology, v. 25, n. 3, p. 213-222, 2013.
PINCELLI, R. P.; SILVA, M. A. Alterações morfológicas foliares em cultivares de canadeaçúcar em resposta à deficiência hídrica. Bioscience Journal, v. 28, n. 4, p. 546-556, 2012.

RICHARDS, L.A. Physical conditions of water in soil. In: BLACK. C.A.; EVANS, D.D.; WHITE, J.L.; CLARK, F.E. (ed.) Methods of soil analysis - physical and mineralogical properties, including statistics of measurements and sampling. Madison, ASASSSA, p. 128-152, 1965.

SARAIVA, G. F. R.; ANDRADE, R. S.; SOUZA, G. M. Termografia por infravermelho como ferramenta de diagnóstico precoce de estresse hídrico severo em soja. Agrarian Academy, v. 1, n. 2, p. 158-169, 2014.

SILVA, M. A.; JIFON, J. L.; SILVA, J. A. G.; SHARMA, V. Use of physiological parameters as fast tools to screen for drought tolerance in sugarcane. Brazilian Journal of Plant Physiology, v. 19, p. 193-201, 2007.

SILVA, M. A.; JIFON, J. L.; SILVA, J. A. G.; SANTOS, C. M.; SHARMA, V. Relationships between physiological traits and productivity of sugarcane in response to water deficit. The Journal of Agricultural Science, v. 152, n. 01, p. 104-118, 2012.

SILVA. M. A.; SANTOS, C. M.; ARANTES, M. T.; BRUNELLI, M. C.; HOLANDA, L. A. Respostas fisiológicas de cultivares de cana-de-açúcar submetidas à deficiência hídrica e a reidratação. Revista Caatinga, v. 26, n. 3, p. 28-35, 2013.

SILVA, M. A.; SANTOS, C. M.; VITORINO, H. S.; RHEIN, A. F. L. Pigmentos fotossintéticos e índice SPAD como descritores de intensidade do estresse por deficiência hídrica em cana-de-açúcar. Bioscience Journal, v. 30, p. 173-181, 2014.

VAN DILLEWIJN C. Botany of sugarcane. Chronica Botanica, Waltham, 1952. 
Maia Júnior et al.

VIEIRA, G. H. S.; MANTOVANI, E. C.; hídrico para a cultura da cana-deSEDIYAMA, G. C.; DELAZARI, F. T. açúcar em função de lâminas de irrigação. Indicadores morfo-fisiológicos do estresse Bioscience Journal, v. 30, n. 1, p. 65-75, 2014. 